\title{
Bilateral Thalamic Glioma
}

\author{
-Case Report-
}

\author{
Masafumi UCHINO, Satoru KITAJIMA, Chikao MIYAZAKI, \\ Iekado SHIBATA, and Myouta MIURA*
}

Departments of Neurosurgery and *Pathology, Toho University School of Medicine, Tokyo

\begin{abstract}
A 35-year-old woman presented with a bilateral thalamic glioma manifesting as dysesthesia over the left side of the body and mental deterioration. $T_{1}$-weighted magnetic resonance imaging revealed enlarged bilateral thalami with homogeneous isointensity and no enhancement after gadolinium administration. Histological examination of a stereotactic biopsy specimen identified anaplastic astrocytoma. Radiotherapy and chemotherapy failed to arrest tumor growth. She subsequently died. Magnetic resonance imaging and clinical findings support the view that bilateral thalamic gliomas represent a distinct clinicopathologic entity among thalamic tumors.
\end{abstract}

Key words: glioma, bilateral thalamic tumor, personality changes, thalamus

\section{Introduction}

Thalamic tumors account for approximately $1 \%$ to $1.5 \%$ of all brain tumors, and are usually unilateral astrocytoma. ${ }^{3,7,9,13)}$ Primary thalamic gliomas include a distinct type known as bilateral thalamic glioma, which occurs as a large tumor located in symmetrical areas in the bilateral thalami, and typically manifesting as behavioral impairments varying from personality changes to frank dementia. This type of thalamic tumor can be distinguished clinically and radiologically from other gliomas. We present a case of bilateral thalamic glioma manifesting as personality change and memory impairment in the absence of hydrocephalus.

\section{Case Report}

A 35-year-old woman presented with a feeling of heaviness in the head and dysesthesia over the left side of the body. Six months earlier, she had begun to show a decline in physical and mental activity, and diminished verbal output. She had developed disturbance of recent memory. Neurological examination found hemianopia on the left. Fundus examination detected no papilledema. Recent memory impairment and dyscalculia were noted. The Wechsler Adult Intelligence Scale-Revised scores suggested

Received February 14, 2002; Accepted July 8, 2002 dementia with verbal intelligence quotient (IQ) 67, performance IQ 54, and overall IQ 56. Computed tomography (CT) showed bilateral isodense thalamic masses without contrast enhancement. $\mathrm{T}_{1}$-weighted magnetic resonance (MR) imaging showed enlarged bilateral thalami with isointensity and no enhancement after gadolinium administration (Fig. 1A, B). The enlarged thalami protruded into the third and lateral ventricles (Fig. 1D). $\mathrm{T}_{2}$-weighted $\mathrm{MR}$ imaging demonstrated essentially homogeneous hyperintense areas in the bilateral thalami (Fig. 1C). Extension into the pulvinars of the bilateral thalami was seen abutting the posterior limb of the internal capsule without involving the corpus callosum or the rostral midbrain. Vertebral and internal carotid angiography revealed a faint tumor stain supplied from the posterior cerebral artery on each side (Fig. 2).

Stereotactic biopsy was performed. Histological examination showed tumor cells with scant eosinophilic cytoplasm and hyperchromatic nuclei, increased cellularity, and mitoses. The tumor cells had diffusely infiltrated but showed no vascular proliferation or necrosis (Fig. 3). The MIB-1 labeling index of the specimen was $11.1 \%$. The diagnosis was anaplastic astrocytoma. Radiotherapy was performed with an overall dose of $60 \mathrm{~Gy}$. Chemotherapy including carboplatin $(30 \mathrm{mg} /$ day $\times 6$ wks $)$ was given, but MR imaging showed no change in tumor size. The patient died 12 months after the initial presentation. 

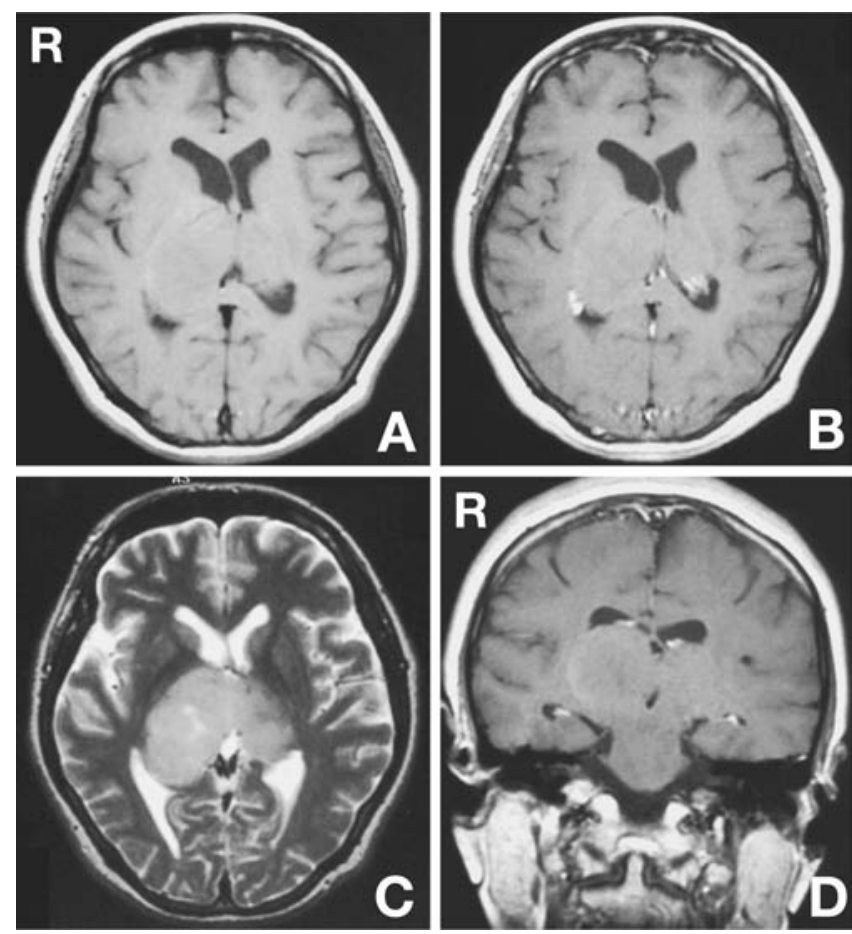

Fig. 1 A: Axial $\mathbf{T}_{1}$-weighted magnetic resonance (MR) image showing enlarged bilateral thalami with isointense signal. B: Axial $\mathrm{T}_{1}$-weighted MR image after gadolinium administration showing no enhancement of the bilateral thalami. C: Axial $\mathrm{T}_{2}$-weighted MR image showing prominent hyperintense areas in the bilateral thalami. D: Coronal $T_{1}$-weighted MR image showing extension of the thalami to the medial temporal lobes.

\section{Discussion}

Bilateral thalamic glioma is extremely rare, with only known 16 cases including the present case (Table 1). ${ }^{4-6,10,11,15)}$ The patients were nine men and seven women aged from 8 to 70 years (mean 39 years). Principal symptoms included personality change, confusion, memory loss, apathy, emotional lability, and dementia. Personality change and mental deterioration with relative sparing of motor and sensory functions are distinctive symptoms.

Increased intracranial pressure is commonly associated with thalamic tumor. ${ }^{3,9,13)}$ Symptoms particularly associated with hydrocephalus, including headache and vomiting, are common, as well as signs of mental deterioration. Unilateral thalamic tumor was associated with hemiparesis in $48-75 \%$ and headache in $56-68 \%$ of patients. ${ }^{1,2,8,14)}$ Hydrocephalus was found in $50 \%$ of patients, ${ }^{14)}$ and placement of cerebrospinal fluid shunts at the time of first

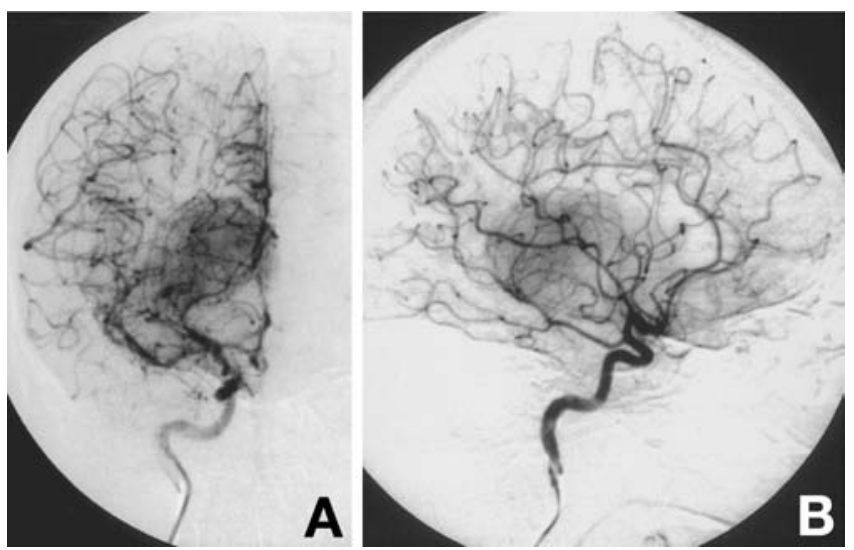

Fig. 2 Right internal carotid angiograms, anteroposterior (A) and lateral views (B), showing a faint tumor stain supplied from the posterior cerebral artery.

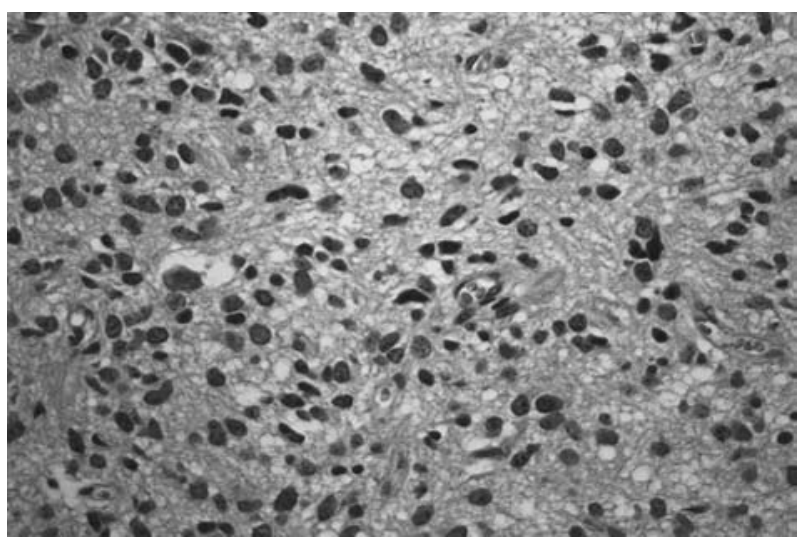

Fig. 3 Photomicrograph of the stereotactic biopsy specimen showing anaplastic astrocytoma. The glial tumor is highly cellular with nuclear pleomorphism and mitotic figures. No focal necrosis or vascular endothelial proliferation is seen. HE stain, $\times 250$.

presentation was required in $62 \%$ of patients. ${ }^{1)}$

Such symptoms are uncommon in the early stages of bilateral thalamic glioma, as only two of the 16 patients had headache, none had hemiparesis, and only one exhibited moderate hydrocephalus. The symptoms of bilateral thalamic glioma may result from dysfunction of the dorsomedial nuclei, which receives connections from the amygdala and temporal neocortex, and projects to the prefrontal area. ${ }^{5}$ Two patterns of presentation of thalamic glioma can be differentiated reflecting the specific anatomic origin. ${ }^{12)}$ In group 1, the tumor originates in the peduncular and capsulothalamic areas and invades the lateral or ventrolateral thalamus, leading to early 
Table 1 Reported cases of bilateral thalamic glioma

\begin{tabular}{|c|c|c|c|c|c|c|c|}
\hline $\begin{array}{l}\text { Case } \\
\text { No. }\end{array}$ & Author (Year) & Age & Sex & Symptoms & Diagnosis & $\begin{array}{l}\text { Glioma } \\
\text { grade }\end{array}$ & $\begin{array}{l}\text { Hydro- } \\
\text { cephalus }\end{array}$ \\
\hline 1 & Ziegler et al. (1977) ${ }^{15)}$ & 59 & M & memory impairment & CT, autopsy & IV & none \\
\hline 2 & Gutmann et al. (1990) & 27 & $\mathrm{~F}$ & personality change & CT, MR imaging & - & none \\
\hline 3 & Ruel et al. $(1992)^{11)}$ & 70 & M & disorientation & CT, MR imaging, autopsy & IV & none \\
\hline 4 & & 8 & $\mathrm{M}$ & personality change & CT, MR imaging, biopsy & III & none \\
\hline 5 & Partlow et al. $(1992)^{10)}$ & 8 & $\mathrm{~F}$ & slow mentation & CT, MR imaging, biopsy & I, II & none \\
\hline 6 & & 15 & $\mathrm{~F}$ & personality change & CT, MR imaging & - & none \\
\hline 7 & & 15 & $\mathrm{~F}$ & personality change & CT, MR imaging, biopsy & III, IV & mild \\
\hline 8 & & 35 & M & memory loss, loss of interest & biopsy, autopsy & I, II & mild \\
\hline 9 & & 49 & $\mathrm{M}$ & memory loss, confusion & angiography, autopsy & III, IV & moderate \\
\hline 10 & & 53 & $\mathrm{M}$ & personality change, memory loss & $\begin{array}{l}\text { CT, MR imaging, } \\
\text { angiography, biopsy }\end{array}$ & I, II & mild \\
\hline 11 & & 67 & $\mathrm{~F}$ & progressive dementia & autopsy & I, II & mild \\
\hline 12 & & 68 & $\mathrm{~F}$ & $\begin{array}{l}\text { disorientation, confusion, } \\
\text { memory loss }\end{array}$ & CT, angiography & - & mild \\
\hline 13 & Esteve et al. (1999) ${ }^{4)}$ & 31 & M & $\begin{array}{l}\text { behavioral change, loss of interest, } \\
\text { hemianopsia }\end{array}$ & MR imaging, biopsy & II & none \\
\hline 14 & & 21 & M & $\begin{array}{l}\text { loss of visual acuity, } \\
\text { loss of interest }\end{array}$ & MR imaging, biopsy & II & mild \\
\hline 15 & Hirano et al. $(2000)^{6)}$ & 63 & M & heavy head, memory impairment & MR imaging, biopsy & III & mild \\
\hline 16 & Present case & 35 & $\mathrm{~F}$ & $\begin{array}{l}\text { mental deterioration, } \\
\text { memory impairment }\end{array}$ & CT, MR imaging, biopsy & III & none \\
\hline
\end{tabular}

CT: computed tomography, MR: magnetic resonance, - : no tissue diagnosed.

sensory disturbances. In group 2, or intrinsic thalamic gliomas, the tumor originates in the subependymal glia bordering the third ventricle and expands laterally from the medial nuclei, leading to early mental deterioration. Although astrocytomas in the cerebral hemispheres usually grow along the fiber tracts in the white matter, invasion in bilateral thalamic gliomas tends to stop at interfaces between gray and white matter. The symmetric appearance on MR imaging suggests that bilateral thalamic gliomas originate unilaterally in a central area, but soon extend to the other side via the interthalamic adhesion. ${ }^{12)}$ However, $42 \%$ of patients with unilateral thalamic tumor showed extension into the adjacent structures, but none had extension to the other side of the thalamus. ${ }^{8)}$ The present case is an example of group 2 intrinsic thalamic glioma.

MR imaging has been more useful than CT for investigating bilateral thalamic glioma. Fluid-attenuated inversion recovery imaging and $\mathrm{T}_{2}$-weighted imaging show homogeneous high signal intensities throughout the thalamus. ${ }^{6}$ Histological examination has found grade I to IV gliomas, but seven of 13 were grade III or IV. Malignant astrocytoma may be more common in bilateral thalamic glioma. No correlation of tumor type with age is evident.

Bilateral thalamic glioma has radiologic and clinical features that differ from those of unilateral thalamic tumors. Bilateral thalamic glioma is an important, though infrequent, component of the differential diagnosis for patients with personality change and dementia. These symptoms reflect destruction of the medial and intralaminar nuclei.

\section{References}

1) Beks JWF, Bouma GJ, Journee HL: Tumors of the thalamic region. A retrospective study of 27 cases. Acta Neurochir (Wien) 85: 125-127, 1987

2) Bernstein M, Hoffman HJ, Halliday WC, Hendrick EB, Humphreys RP: Thalamic tumors in children. J Neurosurg 61: 649-656, 1984

3) Cheek WR, Taveras M: Thalamic tumors. J Neurosurg 24: 505-513, 1966

4) Esteve F, Grand S, Rubin C, Hoffmann D, Pasquier B, Graveron-Demilly D, Mahdjoub R, Le Bas JF: MR spectroscopy of bilateral thalamic gliomas. AJNR Am J Neuroradiol 20: 876-881, 1999

5) Gutmann DH, Grossman RI, Mollman JE: Personality changes associated with thalamic infiltration. J Neurooncol 8: 263-267, 1990

6) Hirano H, Yokoyama S, Nakayama M, Nagata S, Kuratsu J: Bilateral thalamic glioma: case report. Neuroradiology 42: 732-734, 2000

7) Kelly PJ: Stereotactic biopsy and resection of thalamic astrocytomas. Neurosurgery 25: 185-194, 1989

8) Krouwer HGJ, Prados MD: Infiltrative astrocytomas of the thalamus. J Neurosurg 82: 548-557, 1995

9) Mckissock W, Paine KWE: Primary tumors of the thalamus. Brain 81: 41-63, 1958

10) Partlow GD, del Carpio-O'Donovan R, Melanson D, Peters TM: Bilateral thalamic glioma: review of eight 
cases with personality change and mental deterioration. AJNR Am J Neuroradiol 13: 1225-1230, 1992

11) Ruel JH, Broussolle E, Gonnaud PM, Jouvet A, Rousselle C, Chazot G: [Bilateral thalamic glioma. A clinicopathological study of 2 cases]. Rev Neurol (Paris) 12: 742-745, 1992 (Fre, with Eng abstract)

12) Smyth GE, Stern K: Tumors of the thalamus, a clinicopathological study. Brain 61: 339-374, 1938

13) Tovi D, Schisano G, Lileqvist B: Primary tumors of the thalamus. J Neurosurg 18: 730-740, 1961

14) Weisberg LA, Dunn D: Thalamic gliomas: Clinical and computed tomographic correlations. Comput
Radiol 7: 229-235, 1983

15) Ziegler DK, Kaufman A, Marshall HE: Abrupt memory loss associated with thalamic tumor. Arch Neurol 34: 545-548, 1977

Address reprint requests to: M. Uchino, M.D., Department of Neurosurgery, Toho University School of Medicine, 6-11-1 Ohmori-nishi, Ohta-ku, Tokyo 143-8540, Japan.

e-mail: uchino0717@yahoo.co.jp. 